\title{
SCIENTIFIC REPORTS

\section{OPEN Activated carbon fibers for toxic gas removal based on electrical investigation: Mechanistic study of \\ p-type/n-type junction structures}

Received: 26 February 2018

Accepted: 16 July 2019

Published online: 08 October 2019

\author{
Byong Chol Bai ${ }^{1}$, Young-Seak Lee ${ }^{1,2} \&$ Ji Sun $\mathrm{Im}^{3,4}$
}

In this study, we evaluated the potential use of CuO-ZnO combination structures with activated carbon fibers (ACFs) for the adsorption (by ACFs) and electrochemical detection (by CuO-ZnO) by of $\mathrm{SO}_{2}$ gas. The gas adsorptivity was concluded to improve as a result of the synergetic effects of physical adsorption by the micropores and mesopores, the specific surface area developed by chemical activation and the chemical adsorption reaction between $\mathrm{SO}_{2}$ and the transition metals introduced in the $\mathrm{CuO}-\mathrm{ZnO}$ combination structures. From comparison of the $\mathrm{SO}_{2}$ sensing properties, the $\mathrm{CuO}-\mathrm{ZnO}$ combination structures with ACFs exhibited the fastest sensing capability. This result can be attributed to the larger specific surface area of the semiconductor, which extended its depletion layer by forming p-type $\mathrm{CuO} / \mathrm{n}$-type $\mathrm{ZnO}$ junctions. This phenomenon led to good $\mathrm{SO}_{2}$ detection through a decrease in the resistance; thus, the contributions of the sensing responses of p-type CuO and n-type $\mathrm{ZnO}$ represent a predominant characteristic of the sensor. These types of mechanisms were proven through various physicochemical and electrical characterization methods, especially through evaluation of the $\mathrm{SO}_{2}$ sensing capability of the $\mathrm{CuO}-\mathrm{ZnO}$ combination structures with ACFs. The reversible sensing capability indicates that the $p-n$ junction structure changed the electrical properties of the ACFs, leading to an intriguing sensing mechanism.

Unlike soil and water pollution, air pollution is not a local problem limited to the country where the pollution source is located; rather, air pollution is an international issue because it spreads over a wide area, including adjacent countries, due to its characteristics ${ }^{1}$. Major air pollutants include $\mathrm{SO}_{\mathrm{x}}, \mathrm{NO}_{\mathrm{x}}, \mathrm{CO}, \mathrm{CO}_{2}$, volatile organic compounds (VOCs), and dust ${ }^{2}$. Previously developed materials with porous structures have been extensively used in industrial purification and chemical recovery applications due to their large specific surface areas and pore volumes. In physical adsorption capacity of activated CFs (ACFs) is largely linked to their pore volume, specific surface area and pore size distribution (PSD) ${ }^{3,4}$. The adsorption of polar molecules, such as $\mathrm{SO}_{\mathrm{x}}$ and $\mathrm{NO}_{\mathrm{x}}$, can also be strengthened by specific interactions with functional groups on the carbon surface ${ }^{5-7}$. In typical industrial conditions, the $\mathrm{SO}_{2}$ adsorption efficiencies primarily depend on the chemical properties of the carbon surface rather than the general textural parameters ${ }^{8,9}$. Additionally, a homogeneous micro-PSD (MPSD) with a mean pore diameter of approximately $7 \AA$ can substantially enhance the $\mathrm{SO}_{2}$ adsorption capacity ${ }^{10,11}$. Therefore, controlling the physical and chemical properties and determining the best combination of these properties are both important for creating ACFs with good adsorption properties. To further improve the gas adsorption properties of such ACFs, studies on strategies for enhancing the adsorption efficiency and catalytic characteristics have been conducted by adding functional groups to the surfaces of ACFs or impregnating the fibers with a transition metal oxide.

In recent decades, $\mathrm{SO}_{\mathrm{x}}$ trapping has been investigated in many studies using a wide variety of metal structures, such as $\mathrm{Cu}, \mathrm{Ag}, \mathrm{Ni}, \mathrm{Fe}, \mathrm{Co}$, and $\mathrm{Pt}$. $\mathrm{Cu}$ has been utilized in many studies because it is inexpensive and exhibits excellent reactivity ${ }^{12-14}$. Moreover, in which two different metal oxides structures have recently become attractive candidates as sensing layers due to their potential to enhance gas sensitivity by a larger modulation in current through the p-n junction barrier than a single metal structure ${ }^{15,16}$.

${ }^{1}$ Chungnam National University, Institute of Chemical and Biological Engineering, Daejeon, 34134, Republic of Korea. ${ }^{2}$ Chungnam National University, Departments of Applied Chemistry and Biological Engineering, Daejeon, 34134, Republic of Korea. ${ }^{3}$ Korea Research Institute of Chemical Technology (KRICT), C-Industry Incubation Center, Daejeon, 34114, Republic of Korea. ${ }^{4}$ University of Science and Technology (UST), Daejeon, 34113, Republic of Korea. Correspondence and requests for materials should be addressed to J.S.I. (email: jsim@krict.re.kr) 
Therefore, these kinds of material should satisfy three main criteria when it needs combination each other. First, the sensor should be useful at room temperature; second, it has to be stable under harsh conditions, such as acidic environments and high temperatures; and finally, it should be highly sensitive to toxic gases. Over the last several decades, ACFs have attracted attention as a promising material that could satisfy the above criteria because ACFs have a high specific surface area for enhanced gas adsorption, excellent electrical properties for high sensitivity and chemical stability for resistance to acidic and high temperature conditions ${ }^{17-19}$. The bottleneck that limits the use of ACFs as a gas sensing material is their insufficient sensitivity to low concentrations of target gases.

So, in this paper, we focused on evaluating the potential use of the prepared ACFs for adsorption and electrochemical detection of $\mathrm{SO}_{2}$ gas. Here, changes in the microtextural properties were caused by pyrolysis of lyocell fibers followed by chemical activation. Also, the roles of various metal oxide dopants, such as zinc oxides and copper oxides, on ACFs in $\mathrm{SO}_{2}$ gas adsorption were investigated. The chemical and textural properties of these carbon materials were evaluated for their potential application in the adsorption of harmful gas.

\section{Results}

Surface morphology. Figure 1 shows SEM images of the surface morphologies of the $\mathrm{ZnO}$ particles and $\mathrm{ZnO} / \mathrm{ACFs}$ ( $\mathrm{ZnA}$ samples) as a function of the $\mathrm{ZnO}$ concentration. Flower-shaped $\mathrm{ZnO}$ structures were formed, and the $\mathrm{ZnO}$ particles were $50 \sim 170 \mathrm{~nm}$ in diameter. According to the EDS analysis, the $\mathrm{Zn}$ and O contents in the $\mathrm{ZnO}$ particles were 58.47 and $41.53 \%$, respectively. The $\mathrm{ZnO}$ particles were dispersed over the fiber surface during the preparation of the $\mathrm{ZnA}$ sample. Additionally, at low concentrations, the shapes of the $\mathrm{ZnO}$ particles were not conducive to growth, and the ability of the ACFs to grow into hexagonal pole shapes was inhibited. SEM images of the $\mathrm{CuO} / \mathrm{ZnO}$ (CZ sample) and $\mathrm{CuO} / \mathrm{ZnO} / \mathrm{ACF}$ (CZA sample) samples are shown in Fig. 1. The $\mathrm{CuO}$ and $\mathrm{ZnO}$ particles aggregated in the $\mathrm{CZ}$ sample, and these aggregates dispersed over the fiber surface in the CZA sample. The SEM images revealed that some of the ACF pores were blocked by the $\mathrm{CuO}$ and $\mathrm{ZnO}$ particles.

Textural properties. The nitrogen adsorption isotherms of the various metal oxide-doped ACFs are presented in Fig. S1. Additionally, a summary of the textural properties of the ACFs samples is presented in Table 1. The pore textures of the ACFs after treatment by the hydrothermal method were investigated by nitrogen adsorption analysis at $-196^{\circ} \mathrm{C}$. As seen in Fig. S1, the adsorption isotherms of the raw and CuA-3 samples showed matched well to Type I adsorption characteristics, indicative of a porous material with micropore diameters smaller than $2 \mathrm{~nm}^{20}$. However, the ZnA-3 and CZA samples show a slightly gentler isotherm curve than the others. Mesopores developed between 0.01 and $0.4 \mathrm{P} / \mathrm{P}_{0}$, and a hysteresis phenomenon was observed, especially in the $\mathrm{ZnA}-3$ sample, due to aggregation of the $\mathrm{ZnO}$ particles during the preparation process, which blocked the pore structures.

As shown in Table 1, the BET specific surface area and pore volume decreased after treatment by the hydrothermal method. The raw sample showed the highest BET specific surface area, whereas the BET specific surface areas of the metal oxide-doped samples were lower. In particular, the specific surface area of ZnA-3 decreased from approximately $925 \mathrm{~m}^{2} / \mathrm{g}$ to $749 \mathrm{~m}^{2} / \mathrm{g}$ relative to that of the raw sample. The pore volume also decreased after treatment by the hydrothermal method. For example, the CZA sample exhibited a total pore volume of $0.289 \mathrm{~cm}^{3} / \mathrm{g}$, almost $0.08 \mathrm{~cm}^{3} / \mathrm{g}$ lower than that of the raw sample.

Surface properties of the CuO-ZnO-doped ACFs. The CuO-ZnO combined sample was characterized using XRD, as shown in Fig. 2. The ZnO flowers exhibited main diffraction peaks corresponding to the (100), (002), and (101) planes; these are the general peaks of the hexagonal wurtzite phase of $\mathrm{ZnO}$. In the CZ samples, the XRD patterns matched the monoclinic phase of $\mathrm{CuO}$ and the hexagonal wurtzite phase of $\mathrm{ZnO}$. No secondary phases were detected. The XRD peaks of $\mathrm{CuO}$ and $\mathrm{ZnO}$ in the $\mathrm{CZ}$ samples became narrower and more intense due to the hydrothermal treatment.

Figure S2 shows the mapping images of the CZA sample obtained from EDS analysis. As shown by the EDS scan, no intermixing or transformations occurred between the $\mathrm{CuO}$ and $\mathrm{ZnO}$ particles. The two types of oxides were confirmed to aggregate together and well disperse on the ACF surface. As shown in Table S1, the amounts of $\mathrm{CuO}$ and $\mathrm{ZnO}$ introduced onto the ACF samples were confirmed to be $8.28 \%$ of $\mathrm{Cu}$ and $5.33 \%$ of $\mathrm{Zn}$ by ICP-MS. Based on these results, some of the ACF pores could blocked by the $\mathrm{CuO}$ and $\mathrm{ZnO}$ particles, resulting in a decrease in the specific surface area. According to comparison of the pore volumes provided in Table 1, the pores were blocked by the metal oxide particles, whereas mid-sized to large pores formed due to the aggregation of $\mathrm{CuO}$ and $\mathrm{ZnO}$.

$\mathrm{SO}_{2}$ adsorption properties. To analyse the adsorption of $\mathrm{SO}_{2}$ in the fixed bed reactor, breakthrough and saturation curves $\left(\mathrm{C}_{\mathrm{t}} / \mathrm{C}_{0}\right.$ vs. time $)$ were generated, and the data were evaluated using the following equation ${ }^{21}$ : effluent volume:

$$
\mathrm{V}_{\mathrm{eff}}=\mathrm{Q} \cdot \mathrm{t}_{\text {total }} \text {, }
$$

where $\mathrm{Q}$ is the volumetric flow rate $(\mathrm{mL} / \mathrm{min})$, and $\mathrm{t}_{\text {total }}$ is the time of $\mathrm{SO}_{2}$ adsorption.

The total uptake capacity $\left(\mathrm{q}_{\text {total }}, \mathrm{mg}\right)$ is given by the following equation ${ }^{22}$ :

$$
q_{\text {total }}=\frac{Q}{1000} \int_{t=0}^{t=t_{\text {total }}} C d t
$$

where $\mathrm{C}$ is the $\mathrm{SO}_{2}$ concentration at each point. 


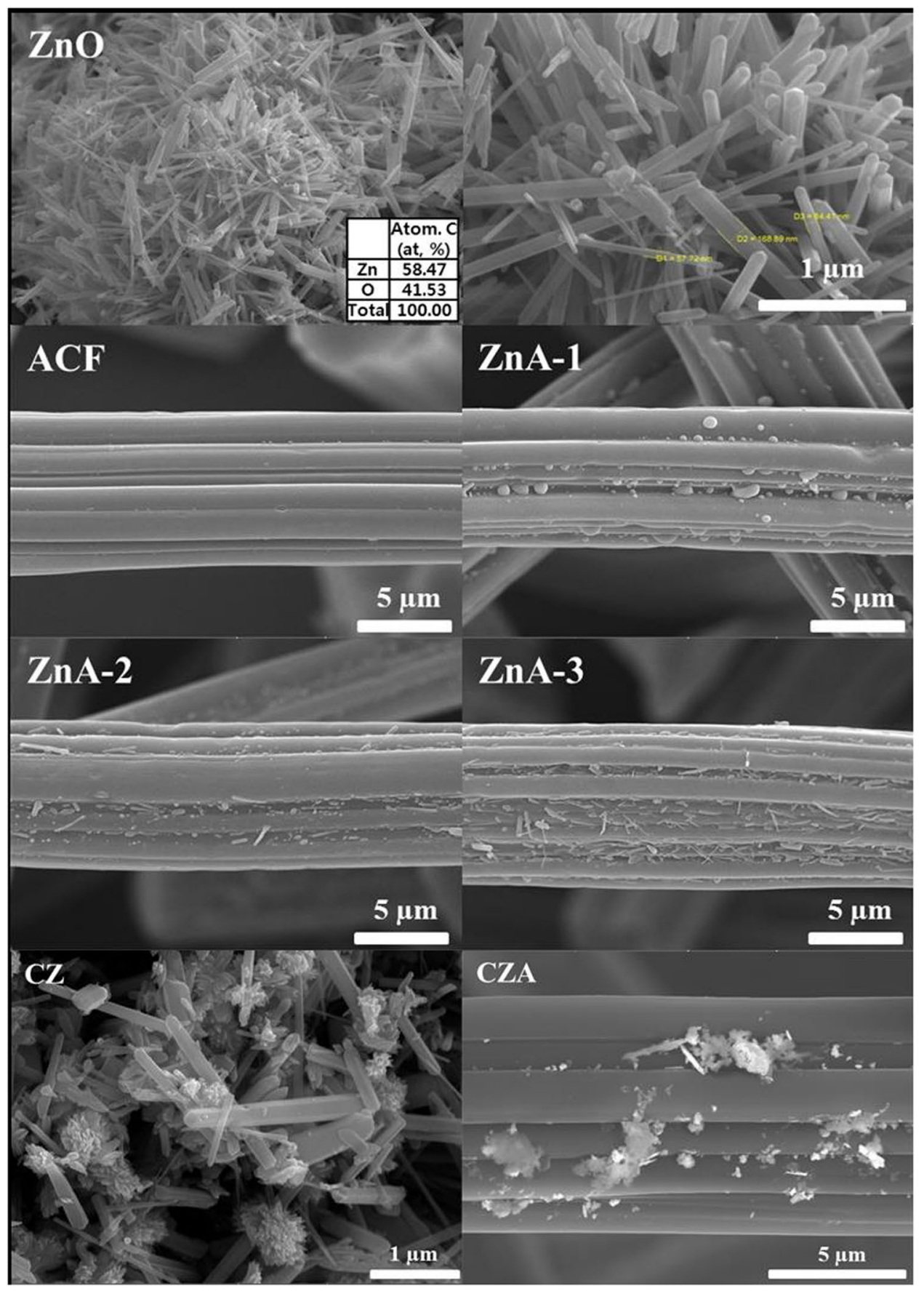

Figure 1. FE-SEM images of $\mathrm{ZnO}, \mathrm{ZnO}$-doped ACFs and $\mathrm{CuO}-\mathrm{ZnO}$ combination with ACFs.

\begin{tabular}{|l|l|l|l|l|l|l|l|}
\hline \multicolumn{2}{|c|}{} & Raw & ZnA-1 & ZnA-2 & ZnA-3 & *CuA-3 & CZA \\
\hline $\begin{array}{l}\text { BET } \\
\text { (specific surface area) }\end{array}$ & $\mathrm{m}^{2} / \mathrm{g}$ & 925 & 828 & 822 & 749 & 874 & 718 \\
\hline $\mathrm{V}_{\text {micro }}$ & $\mathrm{cm}^{3} / \mathrm{g}$ & 0.365 & 0.329 & 0.321 & 0.304 & 0.361 & 0.289 \\
\hline $\mathrm{V}_{\text {meso }}$ & $\mathrm{cm}^{3} / \mathrm{g}$ & 0.027 & 0.044 & 0.061 & 0.034 & 0.027 & 0.041 \\
\hline $\mathrm{V}_{\text {total }}$ & $\mathrm{cm}^{3} / \mathrm{g}$ & 0.392 & 0.373 & 0.382 & 0.338 & 0.388 & 0.330 \\
\hline
\end{tabular}

Table 1. Surface properties of the various metal oxide-doped ACFs. *CuO-sputtered ACFs (Ref. Bai. BC, etc, Materials Chemistry and Physics 200 (2017) 361-367). 


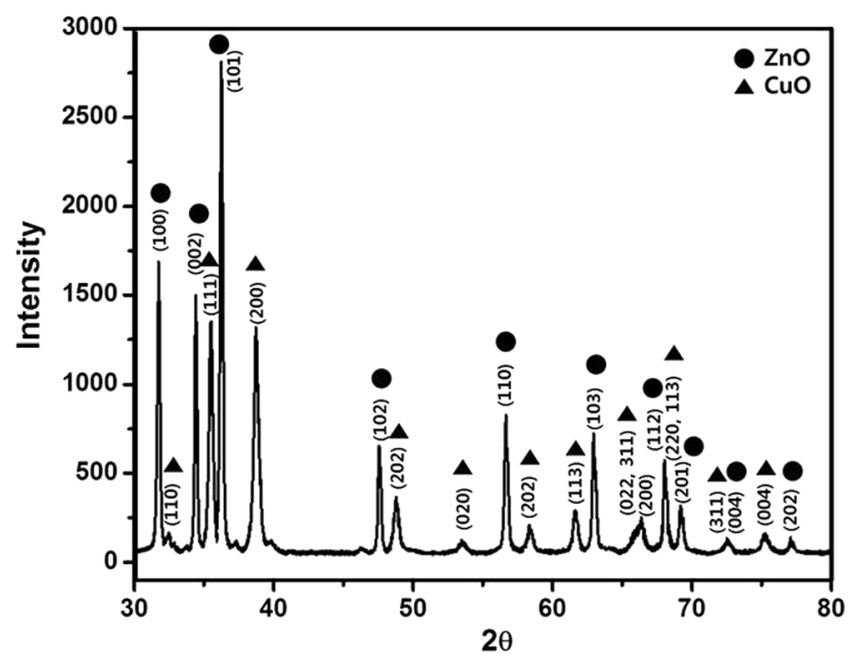

Figure 2. $\mathrm{XRD}$ data for the $\mathrm{CZ}$ sample ( $\mathrm{CuO}-\mathrm{ZnO}$ combination structure).

The total $\mathrm{SO}_{2}\left(\mathrm{~m}_{\text {total }}, \mathrm{mg}\right)$ sent to the reactor and the total $\mathrm{SO}_{2}$ removed $\left(\mathrm{R}_{\text {total }}\right.$, \%) were calculated using the following equation ${ }^{23}$ :

$$
\begin{gathered}
m_{\text {total }}=\frac{C_{0} V_{e f f}}{1000} \\
R_{\text {total }}=\frac{q_{\text {total }}}{m_{\text {total }}} \times 100
\end{gathered}
$$

The length of the mass transfer zone (MTZ), which refers to the length of the bed over which the concentration in the fluid phase changes from an upper value to a lower value, was computed from the breakthrough curve as follows ${ }^{24}$ :

$$
Z_{m}=Z\left(1-\frac{t_{0.05}}{t_{0.95}}\right)
$$

where $Z_{m}$ is the length of the MTZ $(\mathrm{cm}), Z$ is the bed height $(\mathrm{cm}), \mathrm{t}_{0.05}$ is the time at breakthrough (min), and $\mathrm{t}_{0.95}$ is the time at which saturation is reached ( $\mathrm{min})$.

The bed utilization of the fixed bed reactor, $f$, is given by the following equation ${ }^{24}$ :

$$
f=\left(1-\frac{0.5 \times M T Z}{\text { bed height }}\right) \times 100
$$

We studied the adsorption of $\mathrm{SO}_{2}$ in a fixed bed reactor packed with the $\mathrm{CuO}-\mathrm{ZnO}$ combined ACFs to predict the breakthrough and saturation curves. The values were obtained using the formulas above, and the results are shown in Table 2 . One of the main advantages of this model is its ability to predict the breakthrough time $\left(t_{b}\right)$ and saturation time $\left(\mathrm{t}_{\mathrm{s}}\right)$, the latter of which was arbitrarily defined as the time corresponding to $\mathrm{C} / \mathrm{C}_{0}=5 \%$. Compared with the raw sample, the breakthrough and saturation times of the CZA sample increased from 4.74 to $8.79 \mathrm{~min}$ and from 14.65 to $22.02 \mathrm{~min}$, respectively. These results show that $\mathrm{SO}_{2}$ adsorption is due to the combination of the micropores and the ionic interactions imparted by the introduced metal oxide support. The percentage of $\mathrm{SO}_{2}$ removal and adsorption capacity were calculated from the breakthrough curves and are presented in Table 2. The $\mathrm{SO}_{2}$ adsorption capacity increased in the following order: raw $<\mathrm{ZnA}-3<\mathrm{CZA}<\mathrm{CuA}-3$. These results may be attributed to physical adsorption by the micropores and mesopores. Second, the chemical adsorption of $\mathrm{SO}_{2}$ was made possible by the metal oxide support impregnated into the ACF surface. However, the ZnA-3 sample showed a slightly higher $\mathrm{SO}_{2}$ adsorption capacity than that of the raw sample. These results show that $\mathrm{SO}_{2}$ adsorption occurred through weak ionic interactions with the $\mathrm{ZnO}$ support rather than with the $\mathrm{CuO}$ support. The bed utilization factors $(f)$ were calculated from the length of the MTZ, and the CZA sample had an $f$ value of $69.96 \%$, higher than those of the other samples. These phenomena could be explained by the specific surface area and catalyst support because the large specific surface area seemed to interact strongly with the $\mathrm{SO}_{2}$ molecules and exert a greater influence than the catalytic effects did. Therefore, the adsorption efficiency of $\mathrm{SO}_{2}$ should be investigated according to the specific surface area of the ACFs.

Comparison of $\mathrm{SO}_{2}$ adsorption to the BET surface area. We examined the chemical effects induced by the enhanced concentration of the various catalyst supports on $\mathrm{SO}_{2}$ adsorption to the ACFs and observed an evident correlation between the $\mathrm{SO}_{2}$ capacity and the surface properties. Figure 3 presents the $\mathrm{SO}_{2}$ adsorption 


\begin{tabular}{|c|c|c|c|c|c|c|c|c|c|c|c|c|c|}
\hline \multirow[b]{3}{*}{ Sample } & $\begin{array}{l}\text { Superficial } \\
\text { Velocity }\end{array}$ & $\begin{array}{l}\text { Initial } \\
\text { Concentration }\end{array}$ & $\begin{array}{l}\text { Bed } \\
\text { Height }\end{array}$ & $\begin{array}{l}\text { Total } \\
\text { Time }\end{array}$ & $\begin{array}{l}\text { Breakthrough } \\
\text { Time }\end{array}$ & $\begin{array}{l}\text { Stoichiometric } \\
\text { Breakthrough } \\
\text { Time }\end{array}$ & $\begin{array}{l}\text { Saturation } \\
\text { Time }\end{array}$ & $\begin{array}{l}\text { Effluent } \\
\text { Volume }\end{array}$ & $\begin{array}{l}\text { Total } \\
\text { Amount } \\
\text { Removed }\end{array}$ & $\begin{array}{l}\text { Total } \\
\text { Removal }\end{array}$ & $\begin{array}{l}\text { Adsorption } \\
\text { Capacity }\end{array}$ & $\begin{array}{l}\text { Length } \\
\text { of } \\
\text { MTZ }\end{array}$ & $\begin{array}{l}\text { Bed } \\
\text { Utilization }\end{array}$ \\
\hline & $\mathbf{Q}$ & $\mathrm{C}_{0}$ & $\mathrm{Z}$ & $t_{\text {total }}$ & $t_{0.05}$ & $t_{0.5}$ & $t_{0.95}$ & $\mathrm{~V}_{\mathrm{eff}}$ & $\mathbf{m}_{\text {total }}$ & $\mathbf{R}_{\text {total }}$ & $\mathbf{q}_{\text {total }}$ & $\mathbf{L}_{\mathrm{MTZ}}$ & $f$ \\
\hline & $(\mathrm{cc} / \mathrm{min})$ & $(\mathrm{mg} / \mathrm{L})$ & $(\mathrm{cm})$ & (min) & $(\min )$ & (min) & $(\mathrm{min})$ & (cc) & (mg) & $(\%)$ & (mg) & $(\mathrm{cm})$ & $(\%)$ \\
\hline Raw & 1,500 & 40.00 & 2 & 35.02 & 4.74 & 7.92 & 14.65 & 52,533 & 2101.32 & 28.82 & 605.51 & 1.35 & 66.18 \\
\hline$* \mathrm{CuA}-3$ & 1,500 & 40.00 & 2 & 43.60 & 10.21 & 13.38 & 27.65 & 65,400 & 2616.00 & 47.72 & 1248.30 & 1.26 & 68.46 \\
\hline $\mathrm{ZnA}-3$ & 1,500 & 40.00 & 2 & 32.77 & 3.90 & 8.02 & 18.89 & 49,155 & 1966.20 & 31.12 & 611.88 & 1.59 & 60.32 \\
\hline $\mathrm{CZA}$ & 1,500 & 40.00 & 2 & 39.89 & 8.79 & 10.83 & 22.02 & 59,835 & 2393.4 & 43.40 & 1038.74 & 1.20 & 69.96 \\
\hline
\end{tabular}

Table 2. Parameters obtained from the breakthrough curves of $\mathrm{SO}_{2}$ adsorption. ${ }^{*} \mathrm{CuO}$-sputtered ACFs (Ref. Bai. BC, etc, Materials Chemistry and Physics 200 (2017) 361-367).

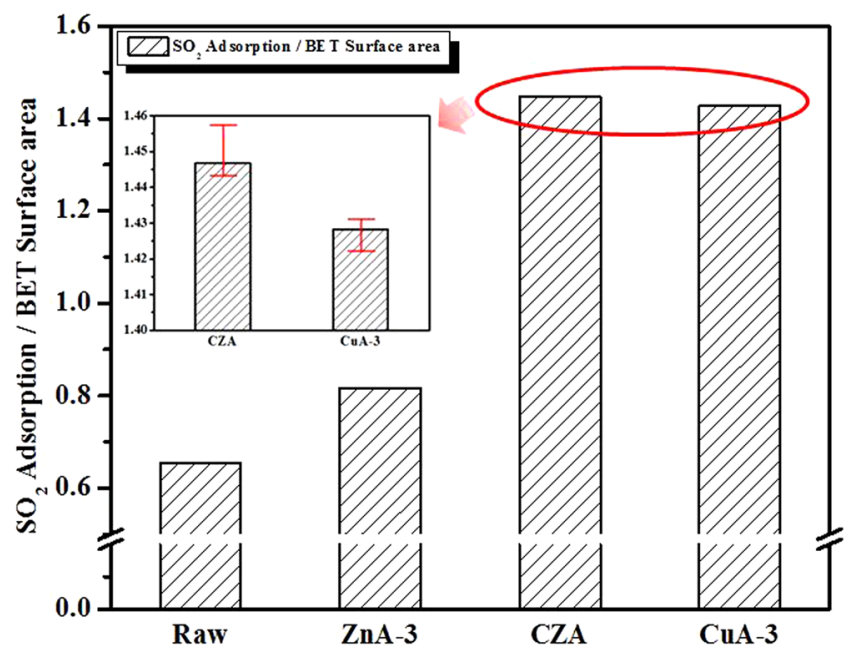

Figure 3. Comparison of the $\mathrm{SO}_{2}$ adsorption capacities according to the BET specific surface area of the various metal oxide-doped ACFs.

capacity according to the BET specific surface area for the treated ACFs. An increase in $\mathrm{SO}_{2}$ adsorption was observed for the ACFs impregnated with the catalyst support. The $\mathrm{SO}_{2}$ adsorption capacity according to the BET specific surface area increased in the order of raw $<\mathrm{ZnA}-3<\mathrm{CuA}-3<\mathrm{CZA}$. These results can be explained by the pore structure and EDS data. The textural properties of the ACFs did not exhibit large structural defects after the surface treatment. In particular, the CZA sample exhibited the highest values among all the samples tested. Based on these results, the $\mathrm{SO}_{2}$ molecules near the pores were concluded to be more strongly effected than the other molecules with a lone pair of electrons by interactions with the $\mathrm{CuO}-\mathrm{ZnO}$ combination structure, generating attractive forces that effected the electrons in the $\mathrm{SO}_{2}$ molecules. These differences in the surface chemical composition are expected to affect the electrochemical properties, as discussed in next section.

Mechanistic study of p-type/n-type junction structure. The resistive response is plotted versus the time of exposure to $\mathrm{SO}_{2}$ in Fig. 4(a) in terms of $\left(R-R_{0}\right) / R_{0}$, where $R$ is the measured resistance and $R_{0}$ is the initial resistance. The raw sample showed a resistive response of approximately $1 \%$ due to the inactive $\mathrm{SO}_{2}$ adsorption sites and the electron hopping effect in the narrow carbon pores ${ }^{25}$. The development of a porous structure and a $\mathrm{ZnO}$ support enhanced the $\mathrm{SO}_{2}$ sensing ability by more than $4 \%$, as shown for $\mathrm{ZnA}-3$. This result is explained by the $\mathrm{n}$-type semiconductor properties of $\mathrm{ZnO}$ : the resistance increases with the adsorption of $\mathrm{SO}_{2}$, which has remaining electrons. Sample $\mathrm{CuA}-3$ exhibited a high gas sensitivity due to the development of abundant copper active sites for $\mathrm{SO}_{2}$ adsorption. The electrical resistance easily changed, and these phenomena could be explained by the pore effect and adsorbed $\mathrm{SO}_{2}$ molecules. Conversely, the CZA sample exhibited a fast sensing capability that can be attributed to the larger specific surface area of the semiconductor, which extends its depletion layer by forming p-type $\mathrm{CuO} / \mathrm{n}$-type $\mathrm{ZnO}$ junctions ${ }^{26,27}$. The microstructural evolution and gas-sensing properties of the $\mathrm{CuO}$ particles on the micron-scale $\mathrm{ZnO}(\mathrm{CuO} / \mathrm{ZnO})$ structures synthesized via a hydrothermal method were studied by Ran Yoo and co-workers ${ }^{28}$. In that report, $\mathrm{CuO}$-doped $\mathrm{ZnO}$-based sensors showed improved sensing capabilities for dimethyl methylphosphonate (DMMP) gas detection. This increased sensing capability could lead to decreased sensing recovery and response times because of an increase in the number of $\mathrm{O}_{2}$ vacancies and surface reactions resulting from modification of the surface via $\mathrm{CuO}$ doping. Additionally, perfectly reproducible $\mathrm{SO}_{2}$ sensing properties with the expected patterns were observed. Figure 4(b) presents the reproducibility results of the samples as $\mathrm{SO}_{2}$ sensors. For these measurements, all samples were tested three times by removing the adsorbed $\mathrm{SO}_{2}$ gases via heating to $150^{\circ} \mathrm{C}$ at a pressure of $1 \times 10^{-3}$ Torr for $10 \mathrm{~min}$. The results revealed almost 

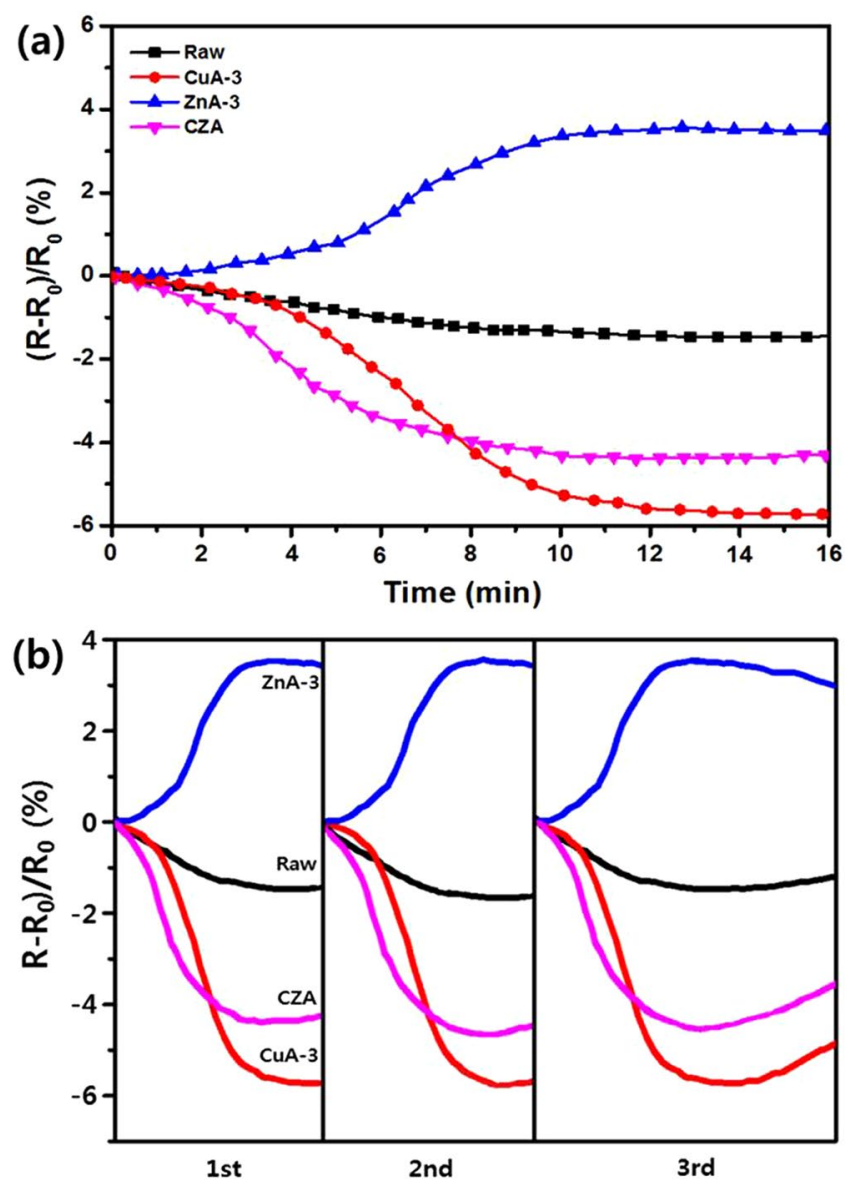

Figure 4. Repeatability of the resistive responses of the various metal oxide-doped ACF gas sensors to repeated $\mathrm{SO}_{2}$ exposure.

perfect reproducibility, which can be attributed to the good desorption properties of the samples during the recovery process. This property is a result of the general advantages of porous carbon materials such as activated carbon and $\mathrm{ACFs}^{29,30}$.

Figure 5 displays a possible mechanism for $\mathrm{SO}_{2}$ detection by the $\mathrm{CuO}-\mathrm{ZnO}$ combination structures with ACFs. In this figure, $\mathrm{CuO}$ particles are randomly dispersed on the $\mathrm{ZnO}$ flower surfaces. When the $\mathrm{CuO}$ particles combine with the $\mathrm{ZnO}$ flowers, a $\mathrm{p} / \mathrm{n}$ junction is formed at the interface between the $\mathrm{p}$-type $\mathrm{CuO}$ particles and the $\mathrm{n}$-type $\mathrm{ZnO}$ flowers. In this mechanism, electrons transfer from the n-type $\mathrm{ZnO}$ to the $\mathrm{p}$-type $\mathrm{CuO}$, and the holes go through the p-type $\mathrm{CuO}$ to the n-type $\mathrm{ZnO}$ until a uniform Fermi level is established in the system, which leads to band bending in the depletion layer. However, when the $\mathrm{CuO}-\mathrm{ZnO}$ combination structures are exposed to $\mathrm{SO}_{2}$, electrons are released through a gas-sensing reaction between $\mathrm{Cu}^{+}$and negatively charged $\mathrm{SO}_{2}{ }^{-}$ions. The reduced $\mathrm{SO}_{2}$ molecules combine with the holes in the $\mathrm{CuO}$, decreasing both the depletion layer and the resistance ${ }^{28}$. This phenomenon leads to good $\mathrm{SO}_{2}$ detection through a decrease in the resistance; thus, the contributions of the sensing responses of the $\mathrm{p}$-type $\mathrm{CuO}$ and $\mathrm{n}$-type $\mathrm{ZnO}$ represent a predominant characteristic of the sensor, and the specific surface area of the ACFs plays an important role in the $\mathrm{SO}_{2}$ sensing properties.

\section{Discussion}

In this work, $\mathrm{CuO}-\mathrm{ZnO}$ combination structures were uniformly grown and aggregated on ACFs using a hydrothermal process. The dispersion and aggregation of $\mathrm{CuO}$ and $\mathrm{ZnO}$ strongly influenced the morphology of the ACFs. The mechanism of pore structure development was altered in the ACFs impregnated with the CuO-ZnO combination structure. The formation of metal oxides was confirmed by XRD analysis, which revealed that the layers were quite uniform and clearly crystallized as $\mathrm{CuO}$ and $\mathrm{ZnO}$. EDS analysis indicated that the $\mathrm{CuO}-\mathrm{ZnO}$ combined ACFs possessed the monoclinic phase of $\mathrm{CuO}$ and the hexagonal wurtzite phase of $\mathrm{ZnO}$ according to the XRD analysis. No intermixing or identity transformations were observed between the $\mathrm{CuO}$ and $\mathrm{ZnO}$ particles, but the particles did aggregate and were dispersed on the ACF surfaces. Some ACF pores were blocked by the $\mathrm{CuO}$ and $\mathrm{ZnO}$ particles, resulting in a decrease in the surface area. Additionally, the pores could be selectively controlled, and a high specific surface area could be obtained by controlling the optimum process variables for introducing $\mathrm{CuO}$ and $\mathrm{ZnO}$ particles.

In the examination of the $\mathrm{SO}_{2}$ adsorption properties, the CZA sample showed a higher capacity for $\mathrm{SO}_{2}$ uptake than the other samples. This phenomenon could be explained by the high $\mathrm{SO}_{2}$ adsorption capability of the $\mathrm{CuO}-\mathrm{ZnO}$-combined ACFs caused by the strong interactions of the $\mathrm{CuO}-\mathrm{ZnO}$ combination structure with $\mathrm{SO}_{2}$. 


\section{p-type $\mathrm{CuO} / \mathrm{n}$-type $\mathrm{ZnO}$ junction structure}
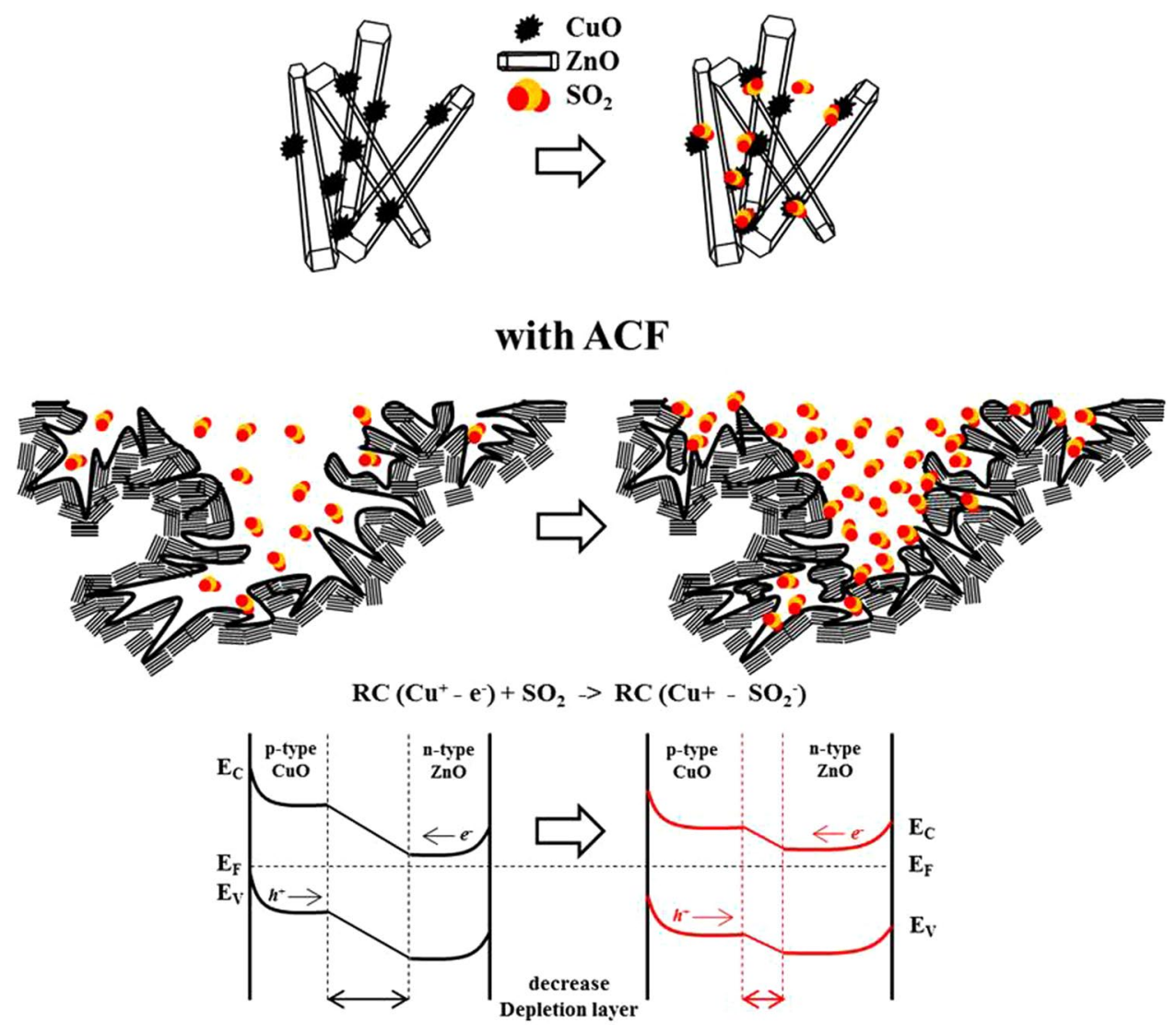

Figure 5. p- $\mathrm{CuO} / \mathrm{n}-\mathrm{ZnO}$ junction structures and their mechanism.

These results demonstrate that the adsorption of $\mathrm{SO}_{2}$ is due to the combination of the micropores in the ACFs and the ionic interactions of the introduced metal oxide support. However, the $\mathrm{ZnA}-3$ sample had a $\mathrm{small}_{\mathrm{SO}_{2}}$ adsorption capacity because $\mathrm{SO}_{2}$ adsorption occurred via weak ionic interactions with $\mathrm{ZnO}$. The polarized $\mathrm{SO}_{2}$ molecules changed the electrical resistance of the ACFs, resulting in good reproducibility and repeatability as a gas sensor. The CZA sample exhibited the most rapid sensing capability, which can be attributed to the extension of the semiconductor depletion layer by forming p-type $\mathrm{CuO} / \mathrm{n}$-type $\mathrm{ZnO}$ junctions. When the $\mathrm{CuO}-\mathrm{ZnO}$ combination structures adsorbed $\mathrm{SO}_{2}$, the electrons of $\mathrm{SO}_{2}^{-}$were released through the gas-sensing reaction with $\mathrm{Cu}^{+}$.

In conclusion, the $\mathrm{p}-\mathrm{n}$ junction structures facilitated the highly sensitive detection of $\mathrm{SO}_{2}$ and decreased the resistance at room temperature. The specific surface areas of the ACFs also played critical roles in improving the $\mathrm{SO}_{2}$ sensing properties. This type of investigation is important for testing the performance of gas adsorbents and sensors in real environments. We focused on evaluating the chemical properties of the prepared ACFs and their potential use for $\mathrm{SO}_{2}$ adsorption. Because adsorption is the basis for gas removal and sensing, these materials can contribute to protection against toxic gases.

\section{Methods}

Materials. Lyocell fibers (Kolon Industries, Republic of Korea) were cut into $20 \mathrm{~cm}$ lengths (approximately $10 \mathrm{~g}$ ). Diammonium hydrogen phosphate (DAHP, Sigma-Aldrich Co., USA) was used to enhance the yield of the lyocell fibers during carbonization. Potassium hydroxide $(\mathrm{KOH},>98 \%$, Samchun Co., Republic of Korea) was used as a chemical activation agent to develop the pore structure. The process was described in detail in our previous study ${ }^{31}$. Zinc acetate dihydrate $\left(\mathrm{Zn}\left(\mathrm{CH}_{3} \mathrm{COO}\right)_{2} \cdot 2 \mathrm{H}_{2} \mathrm{O},>99.999 \%\right.$, Sigma-Aldrich, USA) and sodium hydroxide $(\mathrm{NaOH},>98 \%$, Samchun Co., Republic of Korea) were used as reagents for preparing zinc oxide ( $\mathrm{ZnO})$ on the ACF surface. Additionally, copper (II) nitrate trihydrate $\left(\mathrm{Cu}\left(\mathrm{NO}_{3}\right)_{2} \cdot 3 \mathrm{H}_{2} \mathrm{O},>99.999 \%\right.$, Sigma-Aldrich, USA) was used as a chemical combination agent for the development of $\mathrm{ZnO}$ with copper oxides $(\mathrm{CuO})$.

DAHP treatment of lyocell. DAHP was used for the chemical treatment of the lyocell fibers to enhance the carbonization yield. First, $10 \mathrm{~g}$ of raw lyocell fibers was immersed in $100 \mathrm{ml}$ of 1, 3, 5 and $7 \mathrm{wt} \%$ DAHP solutions for $30 \mathrm{~min}$ at $60^{\circ} \mathrm{C}$. The excess solution was removed by centrifugation, and the samples were dried overnight at $70^{\circ} \mathrm{C}$ under vacuum. The optimal chemical treatment conditions ( $5 \mathrm{wt} \%$ DAHP solution exhibited the best yield enhancement of the lyocell fibers) were determined based on our previous results ${ }^{32}$. 
Preparation of ACFs. Prior to carbonization, the lyocell fibers were stabilized at $300^{\circ} \mathrm{C}$ for $30 \mathrm{~min}$ in air. The stabilized lyocell fibers were heat-treated in a nitrogen atmosphere at $1000^{\circ} \mathrm{C}$ under the following conditions: a heating rate of $10^{\circ} \mathrm{C} / \mathrm{min}$, a holding time of $1 \mathrm{~h}$ and a nitrogen feed rate of $100 \mathrm{ml} / \mathrm{h}$. The samples that were subjected to the heat treatment are referred to as CFs.

A $6 \mathrm{M} \mathrm{KOH}$ solution was prepared as the chemical activation agent based on our previous work ${ }^{33}$. The CFs were placed in an aluminium boat within a reactor. Then, the $\mathrm{KOH}$ solution was added at a concentration of $15 \mathrm{ml} / \mathrm{g}$, and the $\mathrm{CFs}$ were activated at $750^{\circ} \mathrm{C}$ for $3 \mathrm{~h}$ in a nitrogen atmosphere. The heating rate was $5^{\circ} \mathrm{C} / \mathrm{min}$, and the nitrogen feed rate was $100 \mathrm{ml} / \mathrm{min}$. After the reaction, the samples were washed several times with distilled water to remove residual potassium and dried for $24 \mathrm{~h}$ in a $120^{\circ} \mathrm{C}$ oven $^{34}$. The resulting sample was denoted LA (lyocell-based ACFs).

Hydrothermal method. Hydrothermal treatment is the simplest method for generating a relatively uniform dispersion of metal oxides on the ACF surface. $\mathrm{ZnO}$ was prepared from $100 \mathrm{ml}$ of 100, 250, and $500 \mathrm{mmol}$ zinc acetate dihydrate solutions and $100 \mathrm{ml}$ of 100,250, and $500 \mathrm{mmol}$ sodium hydroxide solutions; both types of solution were prepared in distilled water under constant stirring and transferred to an autoclave with the ACFs. The autoclave was heated at $120^{\circ} \mathrm{C}$ for $12 \mathrm{~h}$. The $\mathrm{ZnO}$-treated ACFs were collected by centrifugation and washed several times with methanol. After washing, the ACFs were dried at $80^{\circ} \mathrm{C}$ for $12 \mathrm{~h}$ in air and annealed at $400^{\circ} \mathrm{C}$ for $2 \mathrm{~h}$ in air. The amount of $\mathrm{ZnO}$ that impregnated into the ACFs was quantified using an Inductively coupled plasma mass spectrometry (ICP-MS, Thermo Fisher Scientific iCAP Qc, in Korea Research Institute of Chemical Technology (KRICT)). The manufactured samples are shown in Table S1 and are referred to as ZnA-1, ZnA-2, and $\mathrm{ZnA}-3$ based on the zinc acetate dihydrate concentrations. The ICP-MS results confirmed that 1.34, 3.02, and $6.47 \mathrm{wt} \%$ of $\mathrm{Zn}$, respectively, was introduced into the samples.

Furthermore, the $\mathrm{CuO}-\mathrm{ZnO}$ combined ACFs were prepared from $100 \mathrm{ml}$ of a $500 \mathrm{mmol}$ zinc acetate dihydrate solution and $100 \mathrm{ml}$ of a $500 \mathrm{mmol}$ sodium hydroxide solution; both solutions were prepared in distilled water under constant stirring and transferred to an autoclave with the ACFs. After that, copper (II) nitrate trihydrate ( $50 \mathrm{mmol}$ dissolved in $100 \mathrm{ml}$ of distilled water) was added under constant stirring for $2 \mathrm{~h}$. After this period, the samples were collected by centrifugation and dried at $80^{\circ} \mathrm{C}$ for $12 \mathrm{~h}$ in air.

Physicochemical characterization. To observe the surface characteristics and microstructures of the manufactured samples, field emission scanning electron microscopy (FE-SEM, Hitachi, S-5500, in Korea Basic Science Institute (KBSI) Jeonju Center) coupled with energy dispersive spectrometry (EDS, Quantax 200, Bruker, in KBSI) was used. The textural properties of the prepared ACFs were investigated. The ACF samples were heated under vacuum at $150^{\circ} \mathrm{C}$ for $8 \mathrm{~h}$ to remove water and some of the impurities adsorbed to the samples prior to analysis; the same preparation method was used for the Brunauer-Emmett-Teller (BET) analysis. We chose this strategy because we thought it was important to achieve the same conditions prior to conducting the analysis. The pore structures of the samples were confirmed by $\mathrm{N}_{2}$ adsorption at $-196^{\circ} \mathrm{C}$ using an ASAP2020 instrument (Micromeritics, in KRICT). The specific surface areas of the samples were determined using the BET equations. The PSDs of the samples were determined using the Horvath-Kawazoe (HK) and Barrett-Joyner-Halenda (BJH) methods. The crystallinity and structural properties of the fabricated photocatalysts were characterized using an $\mathrm{X}$-ray diffractometer (XRD, D8 DISCOVER, Bruker AXS, in KRICT) equipped with Cu Ka radiation.

In this study, we used the fixed bed reactor for the $\mathrm{SO}_{2}$ adsorption experiments. In these experiments, $0.1 \mathrm{~g}$ of ACFs was placed in a vertical stainless-steel reactor (internal diameter: $5 \mathrm{~mm}$ ). A thermocouple was placed $1 \mathrm{~mm}$ above the ACF sample to measure the internal bed temperature. The flow was maintained at $1500 \mathrm{cc} / \mathrm{min}$, and the $\mathrm{SO}_{2}$ concentration was approximately $40 \mathrm{ppm}$. The analyser continuously monitored the weight gain, and the outlet $\mathrm{SO}_{2}$ concentrations were continuously measured using a Teledyne model 7600 device (Teledyne Co., in KRICT). The outlet gas composition was recorded every second.

The effects on the sensitivity and response time of the $\mathrm{SO}_{2}$ sensor prepared using the $\mathrm{CuO}$ - $\mathrm{ZnO}$-doped ACFs were investigated. The ACF samples $(0.1 \mathrm{~g})$ were ground using a mortar and dispersed in $5 \mathrm{~g}$ of $\mathrm{N}$, $\mathrm{N}$-dimethylformamide (DMF, Sigma-Aldrich, USA). To disperse ACFs in DMF solution, we used sonicator for $30 \mathrm{~min}$ to uniformly disperse the samples in DMF. After sonication, the ACF solution $(0.01 \mathrm{~g})$ was dropped onto the silicon wafer $\left(0.5 \times 0.5 \mathrm{~cm}^{2}\right)$ using a micropipette (Ovation pipette, Vistalab) and spin-coated (ACE-200 spin-coater) at $900 \mathrm{rpm}$ for $4 \mathrm{~min}$. The spin-coated wafer was heated on a hotplate at $50^{\circ} \mathrm{C}$ for $10 \mathrm{~min}$ to evaporate the DMF. The electrical resistance was measured using a programmable electrometer (Keithley 6514, in KRICT) to evaluate the gas-sensing properties of the prepared sample. This measurement was performed in a $1000-\mathrm{cm}^{3}$ stainless steel chamber. The chamber was connected to gas cylinders $\left(\mathrm{SO}_{2}\right.$ and $\left.\mathrm{N}_{2}\right)$, and the gas flow was controlled using a mass flow controller. The prepared gas sensor sample was placed in a sealed chamber under vacuum at $1 \times 10^{-3}$ Torr. Nitrogen gas was injected into the chamber to stabilize the electrical resistance. Then, 40 ppm of $\mathrm{SO}_{2}\left(\mathrm{~N}_{2}\right.$ balance) was injected into the chamber. The total flow rate of the gas was maintained at $500 \mathrm{cc} /$ min. The change in the electrical resistance was measured at $25 \pm 1{ }^{\circ} \mathrm{C}$.

\section{References}

1. Ioannidou, O. \& Zabaniotou, A. Agricultural residues as precursors for activated carbon production-A review. Renew. Sus. Energy Rev. 11, 1966-2005 (2007).

2. Liu, J., Jin, B., Meng, L. Y. \& Lee, K. H. Synthesis of Polypyrrole-based Nitrogen-containing Porous Carbon Nanotubes for $\mathrm{CO}_{2}$ Adsorption. Carbon Lett. 28, 111-115 (2018).

3. Bai, B. C., Im, J. S. \& Lee, Y. S. Lyocell-based activated carbon fibers improved the adsorption of harmful gas properties when produced via dual-simultaneous treatments. Carbon Lett. 23, 69-73 (2017).

4. Dubinin, M. M. Microporous structures and absorption properties of carbonaceous adsorbents. Carbon 21, 359-366 (1983).

5. Laszlo, K., Tombacz, E. \& Josepovits, K. Effect of activation on the surface chemistry of carbons from polymer precursors. Carbon 39, 1217-1228 (2001). 
6. Muňiz, J., Marban, G. \& Fuertes, A. B. Low temperature selective catalytic reduction of NO over polyarylamide-based carbon fibres. Appl. Catal. B 23, 25-35 (1999).

7. Matzner, S. \& Boehm, H. P. Influence of nitrogen doping on the adsorption and reduction of nitric oxide by activated carbons. Carbon 36, 1697-1703 (1998).

8. Mangun, C. L., DeBarr, J. A. \& Economy, J. Adsorption of sulfur dioxide on ammonia-treated activated carbon fibers. Carbon 39, $1689-1696(2001)$.

9. Muňiz, J., Herrero, J. E. \& Fuertes, A. B. Treatments to enhance the $\mathrm{SO}_{2}$ capture by activated carbon fibres. Appl. Catal. B 18, 171-179 (1998).

10. Raymuňdo-Piňero, E., Cazorla-Amoros, D. \& Linares-Solano, A. Temperature programmed desorption study on the mechanism of $\mathrm{SO}_{2}$ oxidation by activated carbon and activated carbon fibres. Carbon 39, 231-242 (2001).

11. Raymuňdo-Piňero, E., Cazorla-Amoros, D., Salinas-Martinez de Lecea, C. \& Linares-Solano, A. Factors controlling the $\mathrm{SO}_{2}$ removal by porous carbons: relevance of the $\mathrm{SO}_{2}$ oxidation step. Carbon 38, 335-344 (2000).

12. Haruta, M. When gold is not noble: Catalysis by nanoparticles. Chem. Rec. 3, 75-87 (2003).

13. Davis, R. J. All that glitters is not Au-0. Science 301, 926-927 (2003).

14. An, W., Pei, Y. \& Zeng, X. CO oxidation catalyzed by single-walled helical gold nanotube. Nano Lett. 8, 195-202 (2008).

15. Miller, D. R., Akbar, S. A. \& Morris, P. A. Nanoscale metal oxide-based heterojunctions for gas sensing. A Rev. Sens. Act. B 204, 250-272 (2014)

16. Cui, G., Zhang, M. \& Zou, G. Resonant tunneling modulation in quasi-2 $\mathrm{D} \mathrm{Cu}_{2} \mathrm{O} / \mathrm{SnO}_{2} \mathrm{p}-\mathrm{n}$ horizontal-multi-layer heterostructures for room temperature $\mathrm{H}_{2} \mathrm{~S}$ sensor application. Sci. Rep. 3, 1-8 (2013).

17. Schymura, S. et al. Towards efficient dispersion of carbon nanotubes in thermotropic liquid crystals. Adv. Funct. Mater. 20, 3350-3357 (2010).

18. Peng, G., Trock, E. \& Haick, H. Detecting simulated patterns of lung cancer biomarkers by random network of single-walled carbon nanotubes coated with nonpolymeric organic materials. Nano Lett. 8, 3631-3635 (2008).

19. Zheming, G. et al. Electrical properties and morphology of highly conductive composites based on polypropylene and hybrid fillers. J. Ind. Eng. Chem. 16, 10-14 (2010).

20. Lee, H. W., Kim, J. K. \& Park, Y. K. Adsorptive removal of odour substances and NO and catalytic esterification using empty fruit bunch derived biochar. Carbon Lett. 28, 81-86 (2018).

21. Vijayaraghavan, K., Jegan, J., Palanivelu, K. \& Velan, M. Batch and column removal of copper from aqueous solution using a brown marine alga Turbinaria ornate. Chem. Eng. J. 106, 177-184 (2005).

22. Aksu, Z. \& Gönen, F. Biosorption of phenol by immobilized activated sludge in a continuous packed bed: Prediction of breakthrough curves. Process Biochem. 39, 599-613 (2004).

23. Hasana, S. H., Srivastavaa, P. \& Talatb, M. Biosorption of lead using immobilized aeromonas hydrophila biomass in up flow column system: Factorial design for process optimization. J. Hazardous Mater. 177, 312-322 (2010).

24. Futalan, C. M., Kan, C. C., Dalida, M. L., Pascua, C. \& Wan, M. W. Fixed-bed column studies on the removal of copper using chitosan immobilized on bentonite. Carbohydr. Polym. 83, 697-702 (2011).

25. Chiu, H. S. et al. Electron hopping conduction in highly disordered carbon coils. Carbon 47, 1761-1769 (2009).

26. Zhanga, Y. B., LingLi, J., Zhanga, L. X. \& Bie, L. J. Enhanced ethanol gas-sensing properties of flower-like p-CuO/n- $\mathrm{ZnO}$ heterojunction nanorods. Sens. Actuators B 202, 500-507 (2014).

27. Simon, Q. et al. $\mathrm{CuO} / \mathrm{ZnO}$ nanocomposite gas sensors developed by a plasma-assisted route. Chem. Phys. Chem. 13, 2342-2348 (2012).

28. Yoo, R. et al. Highly selective detection of dimethyl methylphosphonate (DMMP) using CuO nanoparticles/ZnO flowers heterojunction. Sens. Actuators B 240, 1099-1105 (2017).

29. Kopac, T. \& Erdogan, F. O. Temperature and alkaline hydroxide treatment effects on hydrogen sorption characteristics of multiwalled carbon nanotube-graphite mixture. J. Ind. Eng. Chem. 15, 730-735 (2009).

30. Katoch, A. et al. Importance of the nanograin size on the $\mathrm{H}_{2} \mathrm{~S}$-sensing properties of $\mathrm{ZnO} / \mathrm{CuO}$ composite nanofibers. Sens. Actuators $B$ 214, 111-116 (2015).

31. Bai, B. C., Lee, H. U., Lee, C. W., Lee, Y. S. \& Im, J. S. $\mathrm{N}_{2}$ plasma treatment on activated carbon fibers for toxic gas removal: Mechanism study by electrochemical investigation. Chem. Eng. J. 306, 260-268 (2016).

32. Bai, B. C. et al. Improved flame-retardant properties of lyocell fiber achieved by phosphorus compound. Mater. Lett. 135, 226-228 (2014).

33. Im, J. S., Park, S. J. \& Lee, Y. S. Superior prospect of chemically activated electrospun carbon fibers for hydrogen storage. Mater. Res. Bull. 44, 1871-1878 (2009)

34. Shamsi Jazeyi, H. \& Kaghazchi, T. Investigation of nitric acid treatment of activated carbon for enhanced aqueous mercury removal. J. Ind. Eng. Chem. 16, 852-858 (2010).

\section{Acknowledgements}

This work was supported by the Korea Institute of Energy Technology Evaluation and Planning (KETEP) and the Ministry of Trade, Industry \& Energy (MOTIE) of the Republic of Korea (No. 20181110200070, Functional porous composite for mitigating air pollutant by using coal combustion products) and also supported by the KOREA RESEARCH INSTITUTE of CHEMICAL TECHNOLOGY (KRICT) (No. KK1913-10, Fabrication of petroleum pitch based carbon absorbent for removal of hazardous air pollutants (SOx/NOx)).

\section{Author Contributions}

All authors reviewed the manuscript and J.S.I. conceived and supervised.

\section{Additional Information}

Supplementary information accompanies this paper at https://doi.org/10.1038/s41598-019-50707-x.

Competing Interests: The authors declare no competing interests.

Publisher's note Springer Nature remains neutral with regard to jurisdictional claims in published maps and institutional affiliations. 
(c) (i) Open Access This article is licensed under a Creative Commons Attribution 4.0 International License, which permits use, sharing, adaptation, distribution and reproduction in any medium or format, as long as you give appropriate credit to the original author(s) and the source, provide a link to the Creative Commons license, and indicate if changes were made. The images or other third party material in this article are included in the article's Creative Commons license, unless indicated otherwise in a credit line to the material. If material is not included in the article's Creative Commons license and your intended use is not permitted by statutory regulation or exceeds the permitted use, you will need to obtain permission directly from the copyright holder. To view a copy of this license, visit http://creativecommons.org/licenses/by/4.0/.

(C) The Author(s) 2019 